\title{
ERRATUM
}

\section{THE INFLUENCE OF ELECTRIC FIELDS ON THE CONVECTIVE HEAT TRANSFER IN LIQUIDS}

\author{
by G. AHSMANN and R. KRONIG *)
}

Laboratorium voor Technische Physica der Technische Hogeschool, Delft

Due to the use of a wrong value of the temperature coefficient of the wire employed the temperature difference $\theta_{S}$ between the wire

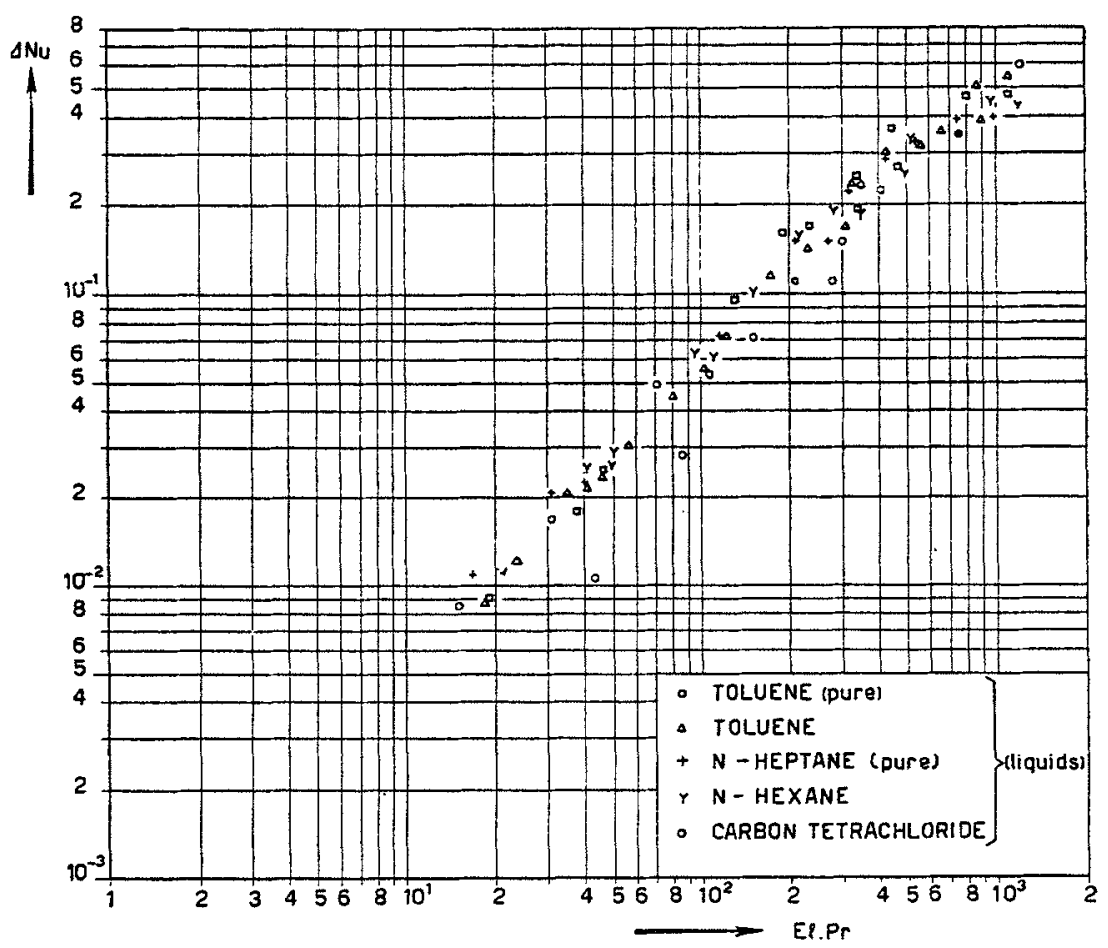

Fig. 3. The change $\Delta N u$ in $N$ u s selt's number for a horizontal wire, due to the application of an electric field, as function of the product $\mathrm{El} \cdot \mathrm{Pr}$ of the electrical characteristic number and Prand th's number.

*) G. Ahsmann and R. Kronig, Appl. sci. Res. A2 (1950) 235. 
and its cold surroundings had to be recomputed. The old $\theta_{S}$ must be multiplied by a factor 5.1 so that the $\theta_{s}$ now become in the successive columns of table I: $36^{\circ}, 55^{\circ}, 65^{\circ}$; table II: $37^{\circ}, 55^{\circ}, 66^{\circ}$; table III $37^{\circ}, 55^{\circ}, 66^{\circ}$; table IV: $38^{\circ}, 60^{\circ}, 69^{\circ}$; table V: $44^{\circ}, 65^{\circ}, 78^{\circ}$; table VII: $245^{\circ}$; the remaining data being unchanged.

In consequence fig. 3 had to be altered as shown. The two points for ammonia have now been omitted, the new temperature difference $\theta_{S}$ being here so large that the assumptions of the theory no longer are fulfilled. A comparison with fig. 1 in the following article by $\mathrm{D}$ e $\mathrm{H}$ a a $\mathrm{n}$ shows a proper agreement between the two series of measurements.

Received 17th May, 1951. 